\title{
INFLUENCE OF THE MANUFACTURING TECHNOLOGY PROCESS ON PROPERTIES OF RAPESEED OIL
}

Karol TUCKI, Department of Organization and Production Engineering, Faculty of Production Engineering, Warsaw University of Life Sciences - SGGW, Nowoursynowska str. 164, 02-787 Warszawa, Poland, arol_tucki@sggw.pl (corresponding author)

Adam KUPCZYK, Department of Organization and Production Engineering, Faculty of Production Engineering, Warsaw University of Life Sciences - SGGW, Nowoursynowska 164 st., 02-787 Warsaw, Poland, k adam_kupczyk@sggw.pl

\begin{abstract}
The article presents results of research regarding the possibility of changing the properties of rapeseed oil thanks to applying diverse press techniques. The main objective of the study was to determine the impact of press parameters and the process of its cleaning on performance and contents of fatty acids in order to get the best parameters of rapeseed oil for fuel purposes. To analyse the ecological diesel engine, analysis shows the results of the quantities of impurities (phosphorus compounds, iodine and water). The research was conducted for oil obtained from six varieties of rapeseed. The parameters of press techniques have a small impact on the contents of individual fatty acids. However, changes of the content of the chemical compounds are dependent on the press parameters to a large extent.
\end{abstract}

Keywords: chemical compounds, parameters, rapeseed oil

\section{INTRODUCTION}

In the past few years European Union member states have been progressively attempting to generate and use energy from renewable sources. Great emphasis is currently being placed on reducing the emissivity of transport, which to date was mainly dependent on crude oil. Consequently studies are being carried out as to the application of diverse fuels for diesel engines to enhance ecological properties. A considerable share is constituted by research on the application of plant fuels for diesel engines (Lotko, 2006; Cisek, 2012; Lotko, 2005; Yunus Khan et al., 2014). The basic technical problem in the universal application of rapeseed oil as fuel is constituted by differences of properties as compared to diesel (Mahmudal et al., 2017). In addition, rapeseed oil tends to lead to formation of sediments and carbon deposits. Despite this the application of raw rapeseed oil as fuel for tractors and other working machines is possible owing to low parameters of engines in those machines (small capacity and rotations). Properties of rapeseed oil as fuel depend on the contents of contamination as compounds of phosphorus, iodine and water. Phosphorus compounds occurring in rapeseed oil in the form of phospholipids may cause the deposition of sludge and emulsion. Water content in rapeseed oil causes the polymerisation of fatty acids and the possibility of scoring of the fuel system elements, while iodine compounds in the oil increase the propensity to deposition of sediments on elements of the engine combustion chamber.

Activities such as selection of rapeseed variety, cultivation technologies, soil conditions, and later on pressing technology or filtration of oil from solid particles are oriented at obtaining the most advantageous parameters of rapeseed oil designated for use as fuel (Gunstone, 2011).

The objective of undertaken studies was to determine pressing parameters (such as: rotational speed of the extractor press, nozzle temperature, temperature, oil cleaning) on the contents of fatty acids, phosphorus, iodine value and water. The research was conducted on diverse varieties of rapeseed:

- low-oil type (contents of oleic acid ca. 30\%),

- medium-oil type (contents of oleic acid ca. $60 \%$ ),

- high-oil type (contents of oleic acid ca. 80\%).

For each of the studied rapeseed varieties 9 samples of rapeseed oil have been pressed. Variable parameters included: rotational speed of the pressing screw $(40,50,60$ or 20, 40, $60 \mathrm{rpm})$ and nozzle diameter $(\varnothing 6, \varnothing 8, \varnothing 10 \mathrm{~mm})$.

\section{METHODOLOGY ADOPTED FOR ANALYSIS}

For needs of testing use was made of the Fermet - Duo auger extractor press with a replaceable diameter of the outlet nozzle and variable rotations of the pressing screw. Preparation process of oil samples comprised the determination of conditions taking place in the process (preliminary pressing) and oil pressing at changed rotational speed and nozzle

Copyright (C) 2017 The Authors. Published by Aleksandras Stulginskis University. This is an open-access article distributed under the terms of the Creative Commons Attribution License (CC-BY 4.0), which permits unrestricted use, distribution, and reproduction in any medium, provided the original author and source are credited. 
(pressing repeated twice). Purification of oil samples from contamination was done by sedimentation (within a time of ca. 50 hours) and filtration. The prepared oil samples were studied in a specialist fuel laboratory, pursuant to binding standards, to enable the determination of:

- content of fatty acids according to PN-EN 150 5508,

- phosphorus contents by the spectrometry method according to EN 14107,

- $\quad$ iodine value according to PN-EN 14111 ,

- $\quad$ water content according to PN-EN ISO 12937.

\section{RESULTS}

Rapeseed oil is a highly complex chemical compound that contains different fatty acids, occurring in different proportions and may also change depending on the use of pressing parameters acids (Bocheńska \& Powierża, 2013; Jakóbiec \& Wądrzyk, 2014).

The conducted research (Table 1) has shown that increasing the diameter of the working nozzle at the same rotations impacts the contents of particular acids in oils.

Table 1. Contents of fatty acids (oleic acid, linoleic acid, linolenoic acid and erucic acid) for variable rotational speed and jet diameter.

\begin{tabular}{|c|c|c|c|c|c|c|c|c|c|c|}
\hline \multicolumn{11}{|c|}{ Oil from low oleic rape type } \\
\hline \multirow{4}{*}{ No. } & \multirow{4}{*}{ Type of fatty acids $\%$} & \multicolumn{9}{|c|}{ Nozzle diameter [mm] } \\
\hline & & \multicolumn{3}{|c|}{$\Phi 6$} & \multicolumn{3}{|c|}{$\Phi 8$} & \multicolumn{3}{|c|}{$\Phi 10$} \\
\hline & & \multicolumn{9}{|c|}{ Rotational speed [rpm.] } \\
\hline & & 20 & 40 & 60 & 20 & 40 & 60 & 20 & 40 & 60 \\
\hline 1 & oleic acid & 27,3 & 28,2 & 25,5 & 24,8 & 24,6 & 25,0 & 25,9 & 24,8 & 27,2 \\
\hline 2 & linoleic acid & 18,8 & 17,4 & 15,9 & 16,0 & 16,0 & 15,1 & 15,9 & 15,7 & 14,8 \\
\hline 3 & linolenoic acid & 9,2 & 8,4 & 7,1 & 7,2 & 7,2 & 6,7 & 7,2 & 7,1 & 6,3 \\
\hline 4 & erucic acid & 30,1 & 30,0 & 30,8 & 29,7 & 30,0 & 30,9 & 29,0 & 31,8 & 30,3 \\
\hline
\end{tabular}

Oil from medium oleic rape type

\begin{tabular}{|c|c|c|c|c|c|c|c|c|c|c|}
\hline \multirow{4}{*}{ No. } & \multirow{4}{*}{ Type of fatty acids $\%$} & \multicolumn{9}{|c|}{ Nozzle diameter [mm] } \\
\hline & & \multicolumn{3}{|c|}{$\Phi 6$} & \multicolumn{3}{|c|}{$\Phi 8$} & \multicolumn{3}{|c|}{$\Phi 10$} \\
\hline & & \multicolumn{9}{|c|}{ Rotational speed [rpm.] } \\
\hline & & 40 & 50 & 60 & 40 & 50 & 60 & 40 & 50 & 60 \\
\hline 1 & oleic acid & 62.45 & 62.60 & 62.55 & 62.50 & 63.00 & 62.85 & 62.70 & 62.45 & 62.80 \\
\hline 2 & linoleic acid & 19.10 & 19.00 & 18.90 & 19.25 & 19.00 & 19.15 & 18.95 & 19.05 & 19.00 \\
\hline 3 & linolenoic acid & 8.45 & 8.55 & 8.40 & 8.35 & 8.45 & 8.50 & 8.40 & 8.40 & 8.40 \\
\hline 4 & erucic acid & 0,2 & 0,2 & 0,2 & 0,1 & 0,2 & 0,2 & 0,2 & 0,2 & 0,2 \\
\hline
\end{tabular}

Oil from high oleic rape type

\begin{tabular}{|c|c|c|c|c|c|c|c|c|c|c|}
\hline \multirow{4}{*}{ No. } & \multirow{4}{*}{ Type of fatty acids $\%$} & \multicolumn{9}{|c|}{ Nozzle diameter [mm] } \\
\hline & & \multicolumn{3}{|c|}{$\Phi 6$} & \multicolumn{3}{|c|}{$\Phi 8$} & \multicolumn{3}{|c|}{$\Phi 10$} \\
\hline & & \multicolumn{9}{|c|}{ Rotational speed [rpm.] } \\
\hline & & 40 & 50 & 60 & 40 & 50 & 60 & 40 & 50 & 60 \\
\hline 1 & oleic acid & 78.15 & 78.05 & 78.10 & 75.95 & 76.05 & 76.20 & 77.05 & 78.15 & 78.30 \\
\hline 2 & linoleic acid & 8,0 & 8,0 & 8,0 & 7.80 & 7.70 & 7.70 & 8.20 & 8,0 & 8,0 \\
\hline 3 & linolenoic acid & 5.90 & 5.90 & 5.80 & 8.15 & 8.15 & 8.15 & 5.70 & 5.85 & 5.95 \\
\hline 4 & erucic acid & 0,2 & 0.25 & 0.25 & 0.23 & 0,2 & 0.13 & 0,3 & 0.25 & 0,3 \\
\hline
\end{tabular}

Oils from low-oil rapeseed variety were characterised by a similar content of oleic and erucic acids (within the range of ca. 24-32\%), while oils from medium- and high-oil variety of rapeseed were characterised by a much higher percentage of oleic acids (62-78\%). Insignificant differences in results of studies related to the contents of fatty acids in oil obtained at changed pressing parameters may be a consequence of precise filtration of samples.

The conducted analysed have shown that dependencies of studied contaminations depending on pressing parameters are variable.

Based on the results (Table 2) a considerable impact was ascertained on the diameter of outlet nozzle of the extractor press on the contents of phosphorus in pressed oil.

Reduction of the diameter from 10 to $6 \mathrm{~mm}$ caused an almost three-fold increase in the contents of phosphorus compounds in oil (Bocheńska \& Powierża, 2012). The increase of the rotational speed also led to an increase in the contents of the analysed compound. The highest value of phosphorus was recorded for a nozzle with a diameter of 6 mm and rotational speed equal to $60 \mathrm{rpm}$. An increase in the amount of phosphorus may be explained by an increased destruction of cell membranes and membranes made of phospholipids. The release of phospholipids is also dependent of the method of harvesting, drying, storage, moisture content and processing of grains (Gunstrone, 2011).

Furthermore, no evident impact was ascertained of pressing parameters on the on the iodine value. In all oil varieties the iodine value amounted to approx. 90-100 gJ/100g (Fig. 1). 
Table 2. Contents of phosphorus, water and iodine value for the different speed of rotation and jet diameter.

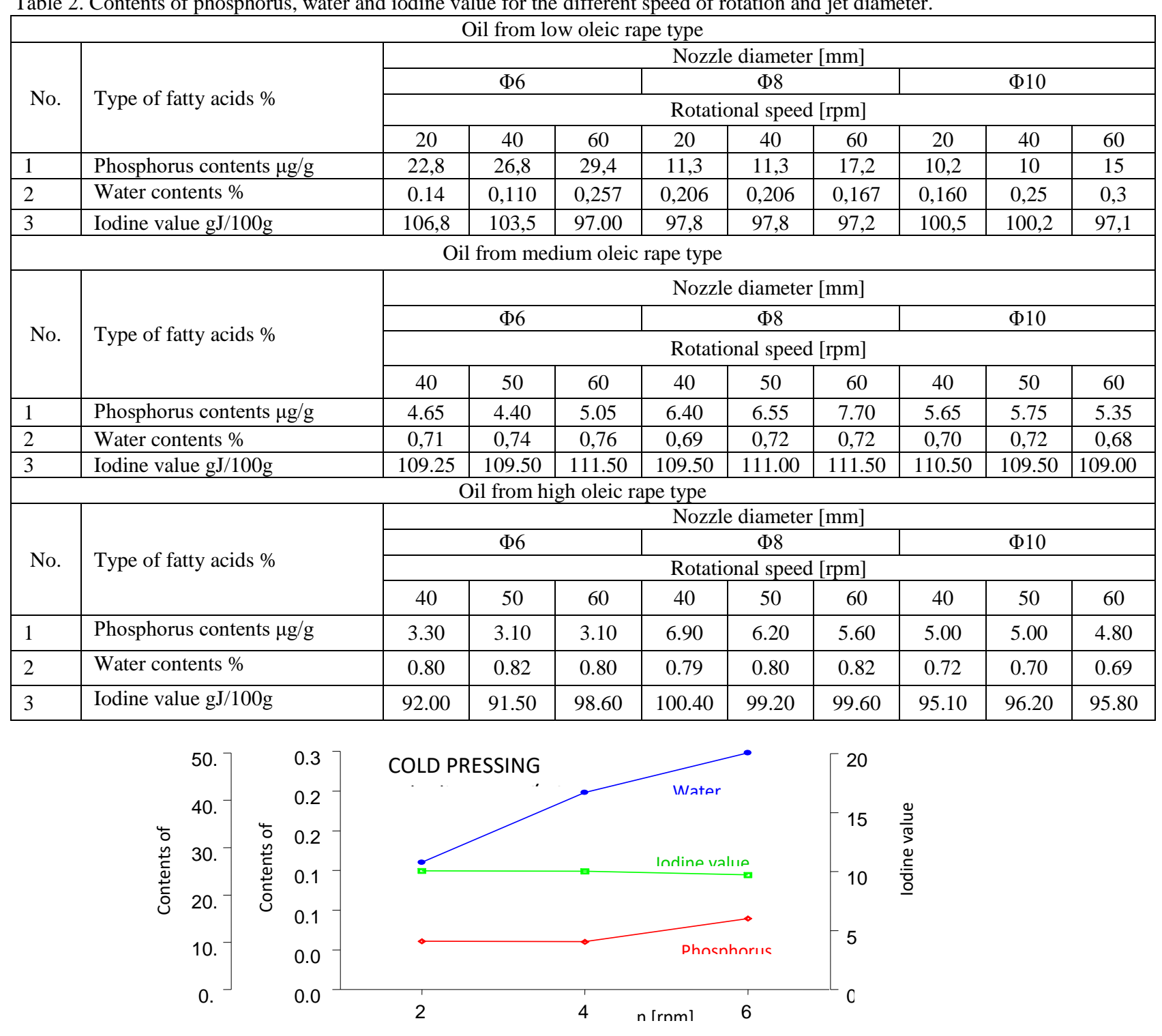

Figure 1. Changes in content of iodine value, water and phosphorus in the function of speed rotation for jet diameter Ø6 mm for lowoil rapeseed variety.

The conducted observations did not point to any evident impact was recorded of pressing parameters on the contents of water. In samples of oil obtained from medium- and high-oil varieties, the contents of water in oil varied within the range of $0.7-0.8 \%$, while significantly lower values of water contents $(0.1-0.2 \%)$ were recorded for samples of soil from low-oil variety.

Based on the conducted studies of oil obtained from high-oil varieties of rapeseed following sedimentation and oil filtration, a certain impact was observed of pressing parameters on the contents of phosphorus, water and the iodine value in oil samples (Wroniak et al., 2013; Mińkowski et al., 2014). After thorough filtration the amount of phosphorus in oil was decreased considerably. Pressing parameters have a smaller impact on the contents of contamination contained in oil after its thorough filtration.

\section{CONCLUSIONS}

The following conclusions may be drawn on the basis of the conducted analyses:

1. The implemented studies of diverse varieties of rapeseed oil (3 varieties) pointed to differences in the contents of fatty acids. Studies of combustion process in a chamber with constant volume were executed with the use of rapeseed oils of low-, medium- and high-oils. The differentiated chemical composition of the tested oils leads to different progress of physical and chemical processes during combustion. 
2. In studies of rapeseed oil obtained at variable cold pressing and sedimentation parameters recorded was an impact of the rotational speed of the extractor press and nozzle diameter on the contents of phosphorus, water and iodine value. Increasing rotational speed and reducing the nozzle caused an increase in the contents of phosphorus compounds even by $100 \%$.

3. Pressing parameters of rapeseed oil and sedimentation affect the contents of compounds of phosphorus, water and iodine value as well as the share of particular fatty. The filtration process reduces the impact of pressing parameters on the contents of contamination.

4. Pressing parameters and the oil purification process should be selected depending on the rapeseed variety and its physical condition (humidity, damage and others). The process of selecting parameters requires a thorough processing of results of studies of the contents of phosphorus, which should be taken into account in optimisation.

5. As regards simplified manufacturing technology of rapeseed oil for own needs, inverters enabling the reduction of rotational speed should be used at the extractor press to reduce phosphorus contents. A technological measure of particular importance in the simplified technology is the application of sedimentation and filtration to lower contamination and phosphorus contents.

To recapitulate, properties of rapeseed oil ad fuel for Diesel engines are affected primarily by the following factors:

- rapeseed variety,

- agrotechnical factors and storage,

- production process of rapeseed oil (pressing, purification).

\section{REFERENCES}

1. Bocheńska A., Powierża L. 2012. Effect of the outlet nozzle diameter on the service properties of the pressed rape-seed oil. Journal of Research and Applications in Agricultural Engineering, Vol. 57 (2), pp. 14-18

2. Bocheńska A., Powierża L. 2013. Effect of the rape variety on the functional property of the rapeseed oil as a fuel. Journal of Research and Applications in Agricultural Engineering, Vol. 58 (2), pp. 17-20

3. Cisek J. 2012. Effect of mixtures rme with diesel oil on the operation parameters of the engine a8C22 in the locomotive SM-42. Technical Transactions. Mechanics 3-M/2012, pp. 8 (109)

4. Gunstone F.D. 2011. Vegetable Oils in Food Technology. Composition, Properties and Uses. Oxford, UK https://doi.org/10.1002/9781444339925

5. Jakóbiec J., Wądrzyk M. 2014. Laboratory studies of rapeseed oil for determination of fatty acids content, Logistyka , Vol. 6, pp. 4731-4738

6. Lotko W. 2005. Estimation of self-ignition delay of a direct-injection diesel engine fuelled with mixtures of diesel oil and rapeseed methyl esters. The Archives of Automotive Engineering, Vol. 4, pp. 321-337

7. Lotko W. 2006 Estimation of exhaust gas emission of diesel engine fuelled with blends of diesel oil with rapeseed oil methyl esters. The Archives of Automotive Engineering, Vol. 4, pp. 403-410

8. Mahmudal H.M., Hagos F.Y., Mamat R., Abdul Adam A., Ishak W.F., Alenezi R. 2017. Production, characterization and performance of biodiesel as an alternative fuel in diesel engines - a review. Renewable and Sustainable Energy Reviews, Vol. 72, pp. 497-509 https://doi.org/10.1016/j.rser.2017.01.001

9. Mińkowski K., Kalinowski A., Krupska A. 2014. Effect of Seed Preparation Method and Seed Mass Choking in Expeller Press on Pressing Parameters and Quality Characteristics of Flax Oil. Food. Science. Technology. Quality, Vol. 4 (95), pp. 75-87

10. Osiak J., Klimkiewicz M., Mruk R., Roszkowski H., Słoma J., Wojdalski J. 2013. Impact of rapeseed oil cold extraction in a screw press on the selected physical and chemical properties of a product as engine fuel, Agricultural Engineering, Vol. 2 (143), pp. 253-261

11. Wroniak M., Ptaszek A., Ratusz K. 2013. Assessing the Effect of Pressing Conditions in Expeller Press on Quality and Chemical Composition of Rapeseed Oil. Food. Science. Technology. Quality, Vol. 1(86), pp. 92-104

12. Yunus Khan T.M., Atabani A.E., Badruddin I.A., Badarudin A., Khayoon M.S., Triwahyono S. 2014. Recent scenario and technologies to utilize non-edible oils for biodiesel production. Renewable and Sustainable Energy Reviews, Vol. 37, pp. 840-851 https://doi.org/10.1016/j.rser.2014.05.064 